\title{
Chloroplast biotechnology, genomics and evolution: current status, challenges and future directions
}

\author{
Jihong Liu Clarke • Henry Daniell • \\ Jacqueline M. Nugent
}

Published online: 18 May 2011

(C) Springer Science+Business Media B.V. 2011

\begin{abstract}
Although the concept of chloroplast transformation was developed two decades ago (Daniell et al. 2002; Maliga 2004), the enormous biotechnological potential of chloroplast transformation has only recently been demonstrated (Daniell et al. 2005; Bock 2007). This is evident in the wide range of products that can be produced in plastids. More than 100 transgenes have been stably integrated and expressed in the chloroplast genome, including genes coding for industrially valuable enzymes, biomaterials, biopharmaceutical proteins, antibodies, antibiotics, vaccine antigens, and genes that confer important agronomic traits (Bock 2007; Verma and Daniell 2007; Daniell et al. 2009; Bock and Warzecha 2010). Extremely high levels of chloroplast-based protein accumulation have been achieved with certain gene constructs illustrating the enormous potential of the technology (Oey et al. 2009; Ruhlman et al. 2010). In addition, chloroplast genetic engineering offers a number of other advantages as a plant-based expression system including multi-gene engineering in a single transformation event, lack of gene silencing and position effects due to site specific transgene integration, minimal or lack of pleiotropic effects due to subcellular compartmentalization of toxic transgene
\end{abstract}

\section{J. L. Clarke $(\bowtie)$}

Plant Health and Protection Division, Bioforsk- Norwegian Institute for Agricultural \& Environmental Research,

Høgskoleveien 7, 1432 Ås, Norway

e-mail: jihong.liu-clarke@bioforsk.no

H. Daniell

Department of Molecular Biology and Microbiology, University of Central Florida, College of Medicine, 336 Biomolecular Science Building, Orlando, FL 32816-2364, USA

J. M. Nugent

Department of Biology, National University of Ireland, Maynooth, Co. Kildare, Ireland products, and transgene containment via maternal inheritance (Daniell et al. 2002; Maliga 2004). Although originally confined to tobacco in land plants and to Chlamydomonas in algae, chloroplast transformation has now been achieved in a much wider range of plant species including economically important crops such as soybean, cotton, Brassica species, potato, tomato, lettuce, sugar beet, eggplant etc. (reviewed by Verma and Daniell 2007; and by Clarke and Daniell in this issue). Despite these major advances in the field major challenges remain. Chloroplast transformation of monocots, including the most important food crops rice, maize, wheat and sorghum has not been successful despite repeated attempts and will require a renewed research effort. It is still difficult to achieve significant levels of transgene expression in plastid types other than chloroplasts and this limits the production of plastid-based products to leaf tissue. Future chloroplast transformation efforts will require a parallel focus on chloroplast genomics. Intergenic spacer regions in chloroplast genomes are not well-conserved and effective vector design for transformation of any new species will require species-specific chloroplast genome sequence data (Ruhlman et al. 2010). Likewise, the use of heterologous gene regulatory elements substantially reduces transgene expression due to transcript instability, differences in affinity for RNA binding proteins and reduced translational efficiency (Ruhlman et al. 2010). More than $45 \%$ of the chloroplast genome comprises intergenic spacer regions where the regulatory elements reside (Verma and Daniell 2007). Although only a handful of crop chloroplast genomes were sequenced until 2005, recent progress in this field is quite impressive with $>35$ chloroplast genomes sequenced (NCBI Organelle Genome, http://www.ncbi.nlm.nih.gov/genomes). However, complete chloroplast genome sequences of many more crop plant species targeted for transformation are needed. 


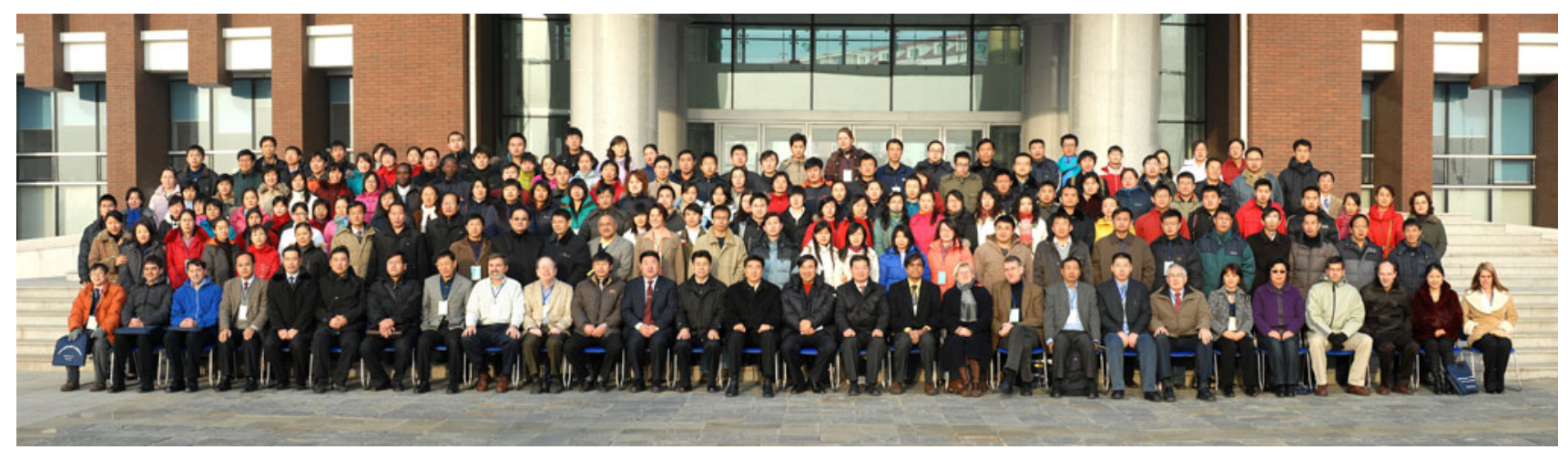

Fig. 1 Group photo from the 1st international symposium on chloroplast genomics and genetic engineering, December 7-9, 2007 in Changchun, China, with 300 participants from 20 countries

Although biotechnologists tend to focus on the chloroplast genomes of crop species, the contribution of non-crop species to our understanding of chloroplast biology and genome evolution has been immense. Studies in non-crop species have revealed the range of evolutionary forces that can impact on the structural dynamics of plastid genomes e.g., variation in nucleotide mutation rates, gene loss events, gene transfer events, loss of introns and other unique features that have greatly contributed not only to our understanding of the basic biology of plastids and plastid genomes but also to resolving aspects of plant phylogeny (Jansen et al. 2007; Magee et al. 2010; Gao et al. 2010). Likewise, most of the basic research directed towards understanding plastid gene regulation (transcription factors, gene regulatory motifs, RNA stability, protein stability, nuclear-plastid interactions) has been carried out in non-crop species (Liere and Börner 2007; SchmitzLinneweber and Small 2008; Stern et al. 2010; Jung and Chory 2010). The levels of recombinant protein accumulation achieved by chloroplast transformation vary enormously ranging from less than $<1 \%$ to more than $70 \%$ (Oey et al.2009; Ruhlman et al. 2010). While we understand how many aspects of gene construct design can impact on protein accumulation levels in the chloroplast, we are a long way from having real predictive power for estimating expression levels for plastid-based transgenes Maintaining a research effort across a broad range of plant species will be necessary in order to develop the most comprehensive view of genome biology and the molecular biology of plastids. This is obviously an important goal in and of itself but the development of sensible and productive approaches to maximize the biotechnological potential of the chloroplast system will also depend on this knowledge. Finally, while therapeutic proteins expressed via the nuclear genome have advanced to phase II and even phase III of human clinical trials (reviewed in Daniell et al. 2009), chloroplast-produced therapeutic proteins have not yet entered clinical studies, although a few have been tested in the field with USDA-APHIS approval (Arlen et al. 2007). More pre-clinical and clinical research is required to showcase the potential of the system and to attract the means to achieve future research funding that will further drive advances in this field. Recent advances in oral delivery of therapeutic proteins offer unique opportunities for the chloroplast system because this is more efficacious than injectable vaccines (Arlen et al. 2008).

An appreciation of the interdependence between research efforts in chloroplast genomics, genome evolution, chloroplast gene regulation and biotechnology spearheaded the establishment of an International Symposium on Chloroplast Genomics and Genetic Engineering (ISCGGE) as a means of bringing together researchers and students from all these areas. The first symposium was held at the Jilin Academy of Agricultural Sciences (JAAS), Changchun, China in 2007 and was organized by Dr. Jihong Liu Clarke (Bioforsk, Norway), Prof. Henry Daniell (University of Central Florida, USA) and local organizers Dr. Dongyun Hao, Dr. Shaochen Xing, Dr Xinzhi Wang and others at JAAS with funding mostly provided by Bioforsk and JAAS. The first symposium attracted 300 participants from 20 countries (Fig. 1). The 2nd ISCGGE was held recently at the National University of Ireland, Maynooth, Co. Kildare, Ireland and was organized by Dr. Jacqueline Nugent. Significant funding for this symposium again came from Bioforsk (Norway), but also from the Science Foundation Ireland and Fáilte Ireland. This symposium hosted oral and poster presentations in the areas of Chloroplast Genomics and Evolution, Chloroplast Biotechnology, Chloroplast Gene Expression and Technology Development. This Special Issue of Plant Molecular Biology offers a selection of peer-reviewed papers originally presented at the 2nd ISCGGE.

After two successful symposia, we look forward to the forthcoming 3rd ISCGGE in the USA in 2012 and to discussing advances, challenges and future directions in the field. Finally, we are grateful for and acknowledge the 
contributions of all symposium participants, local organizers, authors, and manuscript reviewers. We also acknowledge the help of the Editor-in-Chief and the Editorial Office staff of Plant Molecular Biology in facilitating this Special Issue on Chloroplast Biotechnology and Evolution.

\section{References}

Arlen PA, Falconer R, Cherukumilli S, Cole A, Cole AM, Oishi KK, Daniell H (2007) Field production and functional evaluation of chloroplast-derived interferon-alpha2b. Plant Biotechnol J 5:511-525

Arlen PA, Singleton M, Adamovicz JJ, Ding Y, Davoodi-Semiromi A, Daniell H (2008) Effective plague vaccination via oral delivery of plant cells expressing F1-V antigens in chloroplasts. Infect Immun 76:3640-3650

Bock R (2007) Plastid biotechnology: prospects for herbicide and insect resistance, metabolic engineering and molecular farming. Curr Opin Biotechnol 18:100-106

Bock R, Warzecha H (2010) Solar-powered factories for new vaccines and antibiotics. Trends Biotechnol 28:246-252

Daniell H, Khan MS, Alison L (2002) Milestones in chloroplast genetic engineering: an environmentally friendly era in biotechnology. Trends Plant Sci 7:84-91

Daniell H, Kumar S, Dufourmantel N (2005) Breakthrough in chloroplast genetic engineering of agronomically important crops. Trends Biotechnol 23:238-245

Daniell H, Singh ND, Mason H, Streatfield SJ (2009) Plant-made vaccine antigens and biopharmaceuticals. Trends Plant Sci 14:669-679

Gao L, Su YJ, Wang T (2010) Plastid genome sequencing, comparative genomics, and phylogenomics: Current status and prospects. J Sys Evol 48:77-93
Jansen RK, Cai Z, Raubeson LA, Daniell H, dePamphilis CW, Leebens-Mack J, Muller KF, Guisinger-Bellian M, Haberle RC, Hansen AK, Chumley TW, Lee SB, Peery R, McNeal J, Kuehl JV, Boore JL (2007) Analysis of 81 Genes from 64 Plastid Genomes Resolves Relationships in Angiosperms and Identifies Genome-Scale Evolutionary Patterns. Proc Natl Acad Sci USA 104:19369-19374

Jung HS, Chory J (2010) Signaling between chloroplasts and the nucleus: can a systems biology approach bring clarity to a complex and highly regulated pathway? Plant Physiol 152: 453-459

Liere K, Börner T (2007) Transcription and transcriptional regulation in plastids. Top Curr Genet 19:121-174

Magee AM, Aspinall S, Rice DW, Cusack BP, Sémon M, Perry AS, Stefanović S, Milbourne D, Barth S, Palmer JD, Gray JC, Kavanagh TA, Wolfe KH (2010) Localized hypermutation and associated gene losses in legume chloroplast genomes. Genome Res 20:1700-1710

Maliga P (2004) Plastid transformation in higher plants. Annu Rev Plant Biol 55:289-313

Oey M, Lohse M, Kreikemeyer B, Bock R (2009) Exhaustion of the chloroplast protein synthesis capacity by massive expression of a highly stable protein antibiotic. Plant J 57:436-445

Ruhlman T, Verma D, Samson N, Daniell H (2010) The role of heterologous chloroplast sequence elements in transgene integration and expression. Plant Physiol 152:2088-2104

Schmitz-Linneweber C, Small I (2008) Pentatricopeptide repeat proteins: a socket set for organelle gene expression. Trends Plant Sci 13:663-670

Stern DB, Goldschmidt-Clermont M, Hanson MR (2010) Chloroplast RNA metabolism. Annu Rev Plant Biol 61:125-155

Verma D, Daniell H (2007) Chloroplast vector systems for biotechnology applications. Plant Physiol 145:1129-1143 